Research paper

\title{
Kaug-Ida päritoluga puittaimede kasvatamisest Järvseljal
}

\section{Heino Kasesalu}

Kasesalu, H. 2020. The results of cultivating tree and shrub species of Far-Eastern origin at Järvselja, Estonia. - Forestry Studies | Metsanduslikud Uurimused 72, 64-74, ISSN 1406-9954. Journal homepage: http://mi.emu.ee/forestry.studies

\begin{abstract}
This paper is based on a data set of more than 90 years of experience in cultivation of tree and shrub species of Far-Eastern origin at Järvselja Training and Experimental Forest District. The aim of the paper was to estimate the growth and yield of different tree and shrub species in Eastern Estonia. For this purpose, the height and breast height diameter of trees were measured and their cold hardiness estimated in summer 2019. Our study showed that many tree and shrub species of Far-Eastern origin grow quite well in the conditions prevalent in Eastern Estonia. These introduced species have importance mainly in park management.
\end{abstract}

Key words: Abies sp., Larix sp., Picea sp., Pinus sp., cultivation, growth and yield.

Author's address: Järvselja Training and Experimental Forest District, Kastre Parish 62506, Tartu County, Estonia. *e-mail: heino.kasesalu@mail.ee

\section{Sissejuhatus}

Eesti asub kliimavööndis, kus kohalike puu- ja põõsaliikide arv on võrdlemisi tagasihoidlik, see on alla saja. Selle tõttu on siin aastasadade jooksul tuntud suurt huvi teistes maades kasvavate puittaimede vastu. Neid nimetati võõrpuuliikideks ehk eksootideks. Arvatakse, et esimesena introdutseeriti võõrpuuliike Eestisse kloostriaedades (Paivel, 1968). Hiljem hakati neid kasvatama linnaaedades ja mõisaparkides. 19. sajandi teisel poolel tegeles võõrpuuliikide kasvatamise uurimisega Balti Metsaselts, kes organiseeris ka eksootide seemne varumist ja tellimist (Sivers, 1889). Võõrpuuliikide kasvatamise tulemusi ja võimalusi Baltimaades on üldistanud Johann Klinge (1883). Üheks aktiivse- maks võorrpuuliikide kasvatamise uurijaks Eestis 19. sajandi lõpul ja 20. sajandi algul oli Sangaste mõisa omanik Friedrich Berg (1924).

Esimesed katsed võõrpuuliikide kasvatamisel Järvseljal tehti 19. sajandi 80-ndail (Haller, 1929). Sel ajal töötas seal metsaülemana Martin Maurach, kes oli tuntud oma teaduslike huvide poolest. Metsakultuuride rajamisel hakati kohalike puuliikide kõrval katsetama ka mõnede võõramaiste liikidega. Neid istutati metskonna keskuse parki, metsavahtide elamute juurde, teede äärde ja grupiti kohalike puuliikide sekka. Võõrpuuliikide kultiveerimisel oli sel ajal ühest küljest esteetiline, teisest küljest katseotstarbeline eesmärk. Põhiliselt telliti Saksamaalt mitme võõrpuuliigi seemet ja külvati taimlasse, kultuurid rajati aga

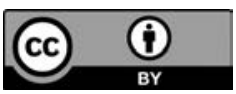

(c) 2020 by the authors. Licensee Estonian University of Life Sciences, Tartu, Estonia. This article is an open access article distributed under the terms and conditions of the Creative Commons Attribution (CC BY) license (http:/ / creativecommons.org/licenses/ by/4.0/). 
peamiselt endisele põllumaale. Sel perioodil kultiveeriti peamiselt Kesk-Euroopast ja Põhja-Ameerika idaosast pärinevaid puuliike. Metskonna keskuse pargis kasvab aga ka ligikaudu 120 a vanune jaapani lehis (Larix kaempferi (Lamb.) Carriere) kõrgusega 37,5 m ja rinnasdiameetriga 92 $\mathrm{cm}$. Pargi rajamiseks olevat istikud toodud Kastre mõisast.

1921. aastal asutati Järvseljale Tartu Ülikooli Õppemetskond (Mathiesen, 1927). Dendroloogiapraktikumi läbiviimiseks üliõpilastele oli tarvis rajada sinna võõrpuuliikide kollektsioon. Taimlate rajamist ning võõrpuuliikide kasvatamist Järvseljal hakkas juhendama hilisem professor Andres Mathiesen (Laas, 1987).

Võõrpuuliikide seemet koguti Eesti vanadest mõisaparkidest ning telliti ka välismaalt, peamiselt Taani ja Austria seemneäridest. Ajavahemikus 1921-1940 introdutseeritud puu- ja põõsaliikidest olid ülekaalus Põhja-Ameerika päritoluga liigid. Sel perioodil ilmusid Järvselja dendroparki ja metsakultuuridesse aga ka mitmed Kaug-Idast pärinevad puu- ja põõsaliigid, mis olid hea kasvuga ja suhteliselt külmakindlad. See on ka loomulik, sest Kaug-Ida floristiline regioon on klimaatiliste tingimuste poolest küllalt sarnane meie riigiga (Ostrat, 1944).

Siinse töö eesmärk on selgitada KaugIda päritoluga puude ja põõsaste kasvu Ida-Eesti tingimustes ning nende kasutamise võimalusi metsanduses ja parginduses. Selleks otstarbeks mõõdeti Järvseljal kasvavate Kaug-Ida päritoluga puittaimede kõrgused ja rinnasdiameetrid. Diameetrid mõõdeti klupega, kõrguste mõõtmiseks kasutati Blume-Leiss kõrgusmõõtjat. Minipuistute takseerimisel kasutati andmete töötlemiseks Andres Kiviste koostatud arvutiprogrammi, mille abil leiti puistu keskmine kõrgus (m), keskmine rinnasdiameeter (cm), rinnaspindala (ruutmeeter/ha) ja tagavara (tm/ha). Puude ja põõsaste kõrgused ning rinnasdiameetrid mõõdeti 2019. aasta suvel.

\section{1-1940 kultiveeritud puittaimed}

\section{Okaspuud}

Nimetatud perioodil kultiveeritud okaspuuliikidest on parimaid tulemusi saadud kuriili lehise (Larix gmelinii (Rupr.) Rupr. var. japonica (Maxim. ex Regel) Pilg.) kasvatamisel. Kuriili lehis ületas Järvselja tingimustes teisi lehise liike kasvukiiruselt, moodustas sirge tüve ning oli suhteliselt vähenõudlik kasvukoha suhtes. Selle liigiga rajati 1930-ndail Järvseljal mitu metsakultuuri, põhiliselt mustika kasvukohatüübis. Parima kasvuga on kvartalil 286 kasvav kultuur, kus 90-aastases puistus kõrgemad puud ületavad $30 \mathrm{~m}$ piiri ja rinnasdiameeter ulatub $44 \mathrm{~cm}$-ni. Seeme nende kultuuride rajamiseks oli saadud Soomest Mustila arboreetumist.

Tabelis 1 on toodud takseeriseloomustused nelja kuriili lehise puistu kohta seisuga 2019. aasta sügisel. Samast perioodist pärineb veel kuriili lehise enamusega puistu kvartalil 45, kuid seal kasvavad I rindes lisaks lehisele veel kuusk, kask ja mänd, mistõttu selle puistu võrdlemine teistega ei ole objektiivne. Samas kasvab aga kvartalil 45 kõige kõrgem $(35 \mathrm{~m})$ ja suurima rinnasdiameetriga $(67 \mathrm{~cm})$ kuriili lehis Järvseljal.

Kvartalil 286 kasvab grupp 1930-ndail istutatud lehiseid, mis siis olid tuntud korea lehise (Larix koreensis Rafn) nime all. Suurima puu kõrgus on nüüd $30 \mathrm{~m}$ ja rinnasdiameeter $46 \mathrm{~cm}$. 1935. aastal rajati metskonna keskuse lähedale ligikaudu kahe hektari suurune dendropark. Harvendatud kasepuistu alla istutati võõrpuuliikide istikuid, peamiselt okaspuid. Kaskede võrad pidid kaitsma istikuid külma eest. Kaug-Ida päritoluga nulgudest istutati sinna järgmised liigid: sahhalini nulg (Abies sachalinensis (F. Schmidt) Mast.), jaapani nulg (A. veitchii Lindl.), nikko nulg (A. homolepis Siebold et Zucc.) ja amuuri nulg (A. nephrolepis (Trautv. ex Maxim.) Maxim.). Sahhalini nulu kõrgus on nüüd $24 \mathrm{~m}$ ja rinnasdiameeter $52 \mathrm{~cm}$. Jaapani nulu grupis on suurima puu kõrgus $27 \mathrm{~m}$ ja rinnasdiameeter $54 \mathrm{~cm}$. Nikko 
Tabel 1. Kuriili lehise puistute takseeriseloomustused.

Table 1. Mean stand characteristics of Larix gmelinii var. japonica.

\begin{tabular}{|c|c|c|c|c|c|c|c|}
\hline $\begin{array}{c}\text { Puistu } \\
\text { asukoht kv / } \\
\text { Situation } \\
\text { of stand } \\
\text { compartment }\end{array}$ & $\begin{array}{l}\text { Puistu } \\
\text { vanus } \\
\text { (a) / } \\
\text { Age of } \\
\text { stand } \\
\text { (yr) }\end{array}$ & $\begin{array}{c}\text { Keskmine } \\
\text { kõrgus } \\
(\mathrm{m}) / \\
\text { Mean } \\
\text { height } \\
(\mathrm{m})\end{array}$ & $\begin{array}{c}\text { Keskmine } \\
\text { rinnasdiameeter } \\
(\mathrm{cm}) / \\
\text { Mean DBH } \\
(\mathrm{cm})\end{array}$ & $\begin{array}{c}\text { Puude } \\
\text { arv } \\
\text { hektaril/ } \\
\text { Number } \\
\text { oftrees } \\
\text { perha }\end{array}$ & $\begin{array}{c}\text { Rinnaspindala } \\
\left(\mathrm{m}^{2} / \mathrm{ha}\right) / \\
\text { Basal area } \\
\left(\mathrm{m}^{2} / \mathrm{ha}\right)\end{array}$ & $\begin{array}{c}\text { Tagavara } \\
\text { (tm/ha) / } \\
\text { Growing } \\
\text { stock } \\
\left(\mathrm{m}^{3} / \mathrm{ha}\right)\end{array}$ & $\begin{array}{c}\text { Keskmine } \\
\text { juurdekasv } \\
\text { (tm/ha) / } \\
\text { Mean } \\
\text { increment } \\
\left(\mathrm{m}^{3} / \mathrm{ha} \text { ) }\right.\end{array}$ \\
\hline 263 & 96 & 28,9 & 32,0 & 515 & 41,6 & 549 & 5,7 \\
\hline 273 & 94 & 29,6 & 32,9 & 480 & 40,8 & 542 & 5,8 \\
\hline 286 & 91 & 28,9 & 31,2 & 698 & 53,4 & 696 & 7,6 \\
\hline 308 & 93 & 26,8 & 30,5 & 600 & 43,8 & 535 & 5,8 \\
\hline
\end{tabular}

nulg külmus karmidel talvedel korduvalt kuni lumepiirini tagasi, säilis ainult lume all olev osa. Kuna viimased talved on olnud suhteliselt pehmed, on puu nüüd 9 m kõrge rinnasdiameetriga $14 \mathrm{~cm}$. Mõnel aastal kandis puu ka käbisid. Amuuri nulg kasvas rahuldavalt, viljus, kuid mõni aasta tagasi puu kuivas.

Kuuseliikidest kasvab dendropargis grupp ajaani kuuski (Picea jezoensis (Sieb. et Zucc.) Carr.), mis noores eas kasvasid väga aeglaselt. Viimastel aastakümnetel on kasv kiirenenud. Ligikaudu 90 aasta vanuselt on suurima puu kõrgus $23 \mathrm{~m}$ ja rinnasdiameeter $38 \mathrm{~cm}$.

Endises Rõkka taimlas kasvab kaks korea kuuske (P. koraiensis Nakai), suurema kõrgus on $21 \mathrm{~m}$ ja rinnasdiameeter $44 \mathrm{~cm}$.

Ida-jugapuu (Taxus cuspidata Sieb. et Zucc.) kasvab dendropargis teiste puude all. Suurim puu on $8 \mathrm{~m}$ kõrge rinnasdiameetriga $14 \mathrm{~cm}$. Võrreldes hariliku jugapuuga (Taxus baccata L.), on see liik Ida-Eesti tingimustes märksa külmakindlam.

\section{Lehtpuud}

Nimetatud perioodil kultiveeritud lehtpuuliikidest kasvab Järvseljal hästi mandžuuria pähklipuu (Juglans mandshurica Maxim.), mis annab idanemisvõimelist seemet. Noores eas kannatab see liik hiliskülmade all, hiljem külmakindlus para- neb. Suurima puu kõrgus ulatub 20 meetrini. On väga dekoratiivne pargipuu.

Amuuri korgipuu (Phellodendron amurense Rupr.) kasvab endises nn Lossiaias kiduravõitu puuna. Suurema puu kõrgus on $10 \mathrm{~m}$ ja rinnasdiameeter $22 \mathrm{~cm}$.

Korea pappel (Populus koreana Rehder.) on kiirekasvuline külmakindel liik. Suurima puu kõrgus Järvseljal on $25 \mathrm{~m}$, rinnasdiameeter $98 \mathrm{~cm}$. Väärib kasvatamist nii pargipuuna kui ka metsakultuurides.

Jaapani tiibpähklipuu (Pterocarya rhoifolia Siebold et Zucc.) kasvab 15 m kõrguse puuna rinnasdiameetriga $24 \mathrm{~cm}$. Viimastel aastatel ei ole külma läbi kannatanud.

Dauuria rododendron (Rhododendron dauricum L.) kasvab kuni 3 m kõrguse põõsana. Külma läbi ei ole kannatanud, mõnel kevadel ôitseb väga rikkalikult.

Amuuri sirel (Syringa amurensis Rupr.) on Järvselja tingimustes kiirekasvuline ja külmakindel liik. Viljub varakult ja annab hea idanevusega seemet. Suurima eksemplari kõrgus on $13 \mathrm{~m}$.

Wolfi sirel (S. wolfii C. K. Schneid.) kasvab Järvseljal kuni 6 m kõrguse põõsana. Külma läbi ei ole kannatanud.

Ginnala vaher (Acer ginnala Maxim.) on külmakindel ja dekoratiivne põõsaliik. Viljub rikkalikult ning seeme on hea idanevusega. Suuremate põõsaste kõrgus ulatub 10 meetrini. Väärib senisest laialdasemat kasutamist pargimajanduses. 
Mandžuuria araalia (Aralia elata (Miq.) Seem. var. mandshurica (Rupr. et Maxim.) J. Wen) kasvab kuni 7 meetri kõrguse põõsana teiste puude turbe all. Karmimatel talvedel külmub tagasi lumepiirini. Väga dekoratiivne liik oma mitmekordselt sulgjate liitlehtede poolest, eriti sügisel värvimuutuse ajal.

Kurdlehine roos (Rosa rugosa Thunb.) on täiesti külmakindel ning vähenõudlik põõsaliik. Leiab kasutamist nii dekoratiivpõõsana kui ka vitamiinirikaste viljade saamiseks.

Enela liikidest kasvavad sellest perioodist Järvseljal kaselehine enelas (Spiraea betulifolia Pall.), jaapani enelas (S. japonica L. f.), keskmine enelas (S. media Schmidt) ja pajulehine enelas (S. salicifolia L.). Kõik need liigid on külmakindlad ja sobivad haljastustöödeks.

Amuuri viinapuu (Vitis amurensis Rupr.) on külmakindel ja kergesti paljundatav liaan. Viljumine on Järvselja tingimustes tagasihoidlik. Dekoratiivse liigina leiab kasutamist vertikaalses haljastuses.

Enne II maailmasõda oli Järvselja üks suurimaid võõrpuuliikide levitamise baase Eestis. Sealsetest taimlatest müüdi istikuid kõigisse Eesti Vabariigi maakondadesse. Seejuures oli istikute hind Järvseljal märgatavalt odavam kui tolleaegsetes eraaiaärides, mis aitas kaasa võõrpuuliikide levitamisele Eestis (Kasesalu, 1962).

\section{0-1980 kultiveeritud puittaimed}

Sõjaeelsetel aastatel oli Järvselja taimlates katsetatud veel mitme Kaug-Ida päritoluga liigi kasvatamist, kuid paljud neist külmusid 1939/40. aasta erakordselt karmil talvel (Mathiesen, 1940). Järgneval aastakümnel võõrpuuliikide introduktsiooniga Järvseljal peaaegu ei tegeldud. Uuesti elavnes see 1953. aastal, mil võõrpuuliikide kasvatamist hakkas juhendama Endel Laas (Veermets, 1962). Alates 1964. aastast introdutseeris võorrpuuliike Järvseljale siinse kirjutise autor. Neil aastail koguti paljude uute võõrpuuliikide seemet meie riigi teistest rajoonidest ning telliti ka väljastpoolt riiki. Mitme puu- ja põõsaliigi seeme saadi Habarovski dendroloogiaaiast, NSVL TA Mägitaiga Katsejaamast Ussuriiski linna lähedal, Primorje Põllumajanduse Instituudi (PPI) ôppe-katsemetsamajandist, Kamtšatka ja Sahhalini metsakatsejaamadest. Mitme liigi seemneid ja noori taimi tõi autor Kaug-Idast kaasa 1965., 1974. ning 1976. a sügisel.

\section{Okaspuud}

Alljärgnevalt on vaadeldud aastail 19601980 kultiveeritud Kaug-Ida päritoluga okaspuude kasvatamise tulemusi Järvseljal. Seejuures on käsitletud põhiliselt neid liike, mida varem Järvseljal ei ole kasvatatud. 1968. aastal alustati Agali külas endisele põllumaale arboreetumi rajamist, kuhu võõrpuuliigid istutati väikeste puistutena. Tabelis 2 on toodud Agali arboreetumis kasvavate Kaug-Ida päritoluga okaspuu puistute takseeriseloomustused.

Kamtšatka nulg - Abies sachalinensis var. gracilis (Kom.) Farjon. Seemned saadi 1976. a Kronoki looduskaitsealalt. Kasvab noores eas väga aeglaselt ja kannatab külma läbi. Agali arboreetumis kannatas ka metskitsede kärpimise all. Nüüd on suurima puukese kõrgus $6 \mathrm{~m}$ ja rinnasdiameeter $8 \mathrm{~cm}$. Pakub huvi vaid kollektsiooniliigina.

Korea nulg - A. koreana E. H. Wilson. Istutati Agali arboreetumisse 1986. a kevadel. Kasvab noores eas väga aeglaselt, hiljem kasv kiireneb. Suurima puu kõrgus on $11 \mathrm{~m}$ ja rinnasdiameeter $20 \mathrm{~cm}$. Viljub varakult. On väga dekoratiivne pargipuu.

Mandžuuria nulg - A. holophylla Maxim. Seeme pärineb PPI õppe-katsemetsamajandist, mis asub Ussuriiski looduskaitseala naabruses. Külvati 1967. a kevadel avamaale. Kasvab noores eas väga aeglaselt ja kannatab hiliskülmade all. Hiljem kasv kiireneb ja külmakindlus paraneb. Nüüd on suuremad puud kuni 19 m kõrged rinnasdiameetriga $34 \mathrm{~cm}$. Käbikandvus on tagasihoidlik. Mandžuuria nulg väärib kasvatamist pargipuuna. 
Tabel 2. Agali arboreetumis kasvavate Kaug-Ida päritoluga okaspuupuistute takseeriseloomustused.

Table 2. Mean stand characteristics of Far-Eastern origin conifers at Agali arboretum.

\begin{tabular}{|c|c|c|c|c|c|c|c|}
\hline $\begin{array}{l}\text { Liik / } \\
\text { Tree species }\end{array}$ & $\begin{array}{l}\text { Puistu } \\
\text { vanus } \\
\text { (a)/ } \\
\text { Age of } \\
\text { stand } \\
\text { (yr) }\end{array}$ & $\begin{array}{c}\text { Keskmine } \\
\text { kõrgus } \\
(\mathrm{m}) / \\
\text { Mean } \\
\text { height } \\
(\mathrm{m})\end{array}$ & $\begin{array}{l}\text { Keskmine } \\
\text { rinnas- } \\
\text { diameeter } \\
(\mathrm{cm}) / \\
\text { Mean DBH } \\
(\mathrm{cm})\end{array}$ & $\begin{array}{c}\text { Puude } \\
\text { arv } \\
\text { hektaril / } \\
\text { Number } \\
\text { oftrees } \\
\text { perha }\end{array}$ & $\begin{array}{c}\text { Rinnas- } \\
\text { pindala } \\
\left(\mathrm{m}^{2} / \mathrm{ha}\right) / \\
\text { Basal area } \\
\left(\mathrm{m}^{2} / \mathrm{ha}\right)\end{array}$ & $\begin{array}{c}\text { Tagavara } \\
\text { (tm/ha) / } \\
\text { Growing } \\
\text { stock } \\
\left(\mathrm{m}^{3} / \mathrm{ha}\right)\end{array}$ & $\begin{array}{c}\text { Keskmine } \\
\text { juurdekasv } \\
\text { (tm/ha) / } \\
\text { Mean } \\
\text { increment } \\
\left(\mathrm{m}^{3} / \mathrm{ha}\right)\end{array}$ \\
\hline Abies holophylla & 51 & 16,6 & 22,6 & 1117 & 44,8 & 368 & 7,2 \\
\hline $\begin{array}{l}\text { Abies } \\
\text { sachalinensis } \\
\text { var. mayriana }\end{array}$ & 56 & 17,5 & 21,3 & 1367 & 48,7 & 421 & 7,5 \\
\hline Abies veitchii & 49 & 19,6 & 27,7 & 1150 & 69,2 & 651 & 13,3 \\
\hline $\begin{array}{l}\text { Larix gmelinii } \\
\text { var. japonica }\end{array}$ & 52 & 20,9 & 28,4 & 583 & 37,0 & 368 & 7,1 \\
\hline $\begin{array}{l}\text { Larix gmelinii } \\
\text { var. olgensis }\end{array}$ & 42 & 23,3 & 29,8 & 533 & 37,1 & 400 & 9,5 \\
\hline Larix kaempferi & 52 & 28,3 & 38,6 & 533 & 62,5 & 784 & 15,1 \\
\hline Picea glehnii & 42 & 16,1 & 19,8 & 1167 & 35,9 & 288 & 6,9 \\
\hline Pinus koraiensis & 43 & 13,8 & 20,3 & 950 & 30,7 & 222 & 5,2 \\
\hline
\end{tabular}

Mayri nulg - A. sachalinensis var. mayriana Miyabe et Kudo. Toodi 1969. a kevadel istikutena Tallinna Botaanikaaiast. Noorelt kannatas tugevasti hiliskülmade all. 1975. a kevadel noored võrsed külmusid ja langesid maha. Seetõttu olid noored puukesed väga omapärase kitsa võraga, meenutasid püramiidvormi. Hiljem puude kasv paranes. Nüüd on suuremad puud 21 m kõrged rinnasdiameetriga $35 \mathrm{~cm}$. Käbikandvus on keskmine.

Jaapani nulg - A. veitchii Lindl. Seemned koguti dendropargis kasvavalt puudegrupilt. Kuivõrd seal läheduses kasvab ka teisi nululiike, on osa arboreetumis kasvavatest jaapani nulgudest hübriidid. Jaapani nulg on suhteliselt kiire kasvuga ja meie oludes külmakindel, seega Eestis perspektiivne pargipuu. Suuremad puud on kuni 22 m kõrged rinnasdiameetriga $48 \mathrm{~cm}$. Mõnel aastal on käbikandvus väga rikkalik.

Kuriili lehis - Larix gmelinii (Rupr.) Rupr. var. japonica (Maxim. ex Regel) Pilg. Toodi 1967. a seemikutena Sahhalini saa- relt. Esimestel aastatel kasvasid taimed suhteliselt aeglaselt, võrreldes kohapealsest seemnest kasvatatud kuriili lehistega, hiljem kasv kiirenes. Nüüd on suuremate puude kõrgus $25 \mathrm{~m}$ ja rinnasdiameeter 44 $\mathrm{cm}$.

Olga lehis - L. gmelinii (Rupr.) Rupr. var. olgensis (A. Henry) Ostenf. et Syrah-Larsen. Seemned koguti 1976. a sügisel Primorje kraist Olga metsamajandist. Okkad muutuvad sügisel kollaseks hiljem kui siberi lehisel - L. sibirica Ledeb. Nüüd on suuremate puude kõrgus $25 \mathrm{~m}$ ja rinnasdiameeter $42 \mathrm{~cm}$.

Jaapani lehis - L. kaempferi (Lamb.) Carriere. Seeme oli kogutud kohapeal kasvavatelt puudelt. Puhkeb kevadel mõnevõrra hiljem teistest lehiseliikidest. Kiirekasvulise ja külmakindlana sobib kasutamiseks haljastuses ning metsakultiveerimisel. Jaapani lehis on oma sinakasrohelise okasti$\mathrm{ku}$ ja peaaegu horisontaalsete okste tõttu omapärane ja dekoratiivne. Suuremate puude kõrgus on $29 \mathrm{~m}$ rinnasdiameetriga kuni $58 \mathrm{~cm}$. 
Dauuria lehis - L. gmelinii (Rupr.) Rupr. var gmelinii. Seemned saadi 1972. aastal amuuri oblastist Belogorski metsamajandist. Noored taimed kasvasid suhteliselt kiiresti, 1975. aastal istutati Agali arboreetumisse. 1982. aastal ulatus suuremate puude kõrgus 8 m-ni (Kasesalu, 1982). 1999. aastal oli arboreetumis kasvavate puude keskmine kõrgus ligi $17 \mathrm{~m}$ (Kasesalu, 1999). Siis aga hakkasid lehised ilma nähtava põhjuseta kuivama ja nüüdseks pole säilinud ühtki puud.

Glehni kuusk - Picea glehnii (Fr. Schmidt) Mast. Seemned saadi Lõuna-Sahhalinilt Korsakovi rajoonist 1976. a sügisel. Kasvab noores eas väga aeglaselt. Külmakahjustusi ei esinenud. Nüüd on suuremate puude kõrgus $18 \mathrm{~m}$ ja rinnasdiameeter $28 \mathrm{~cm}$. Mõnel aastal on olnud rikkalik käbikandvus.

Korea seedermänd - Pinus koraiensis Siebold et Zucc. 1930-ndaist kasvab metskonna keskuse juures asuvas dendropargis kaks korea seedermändi. Nüüd on suurima puu kõrgus $21 \mathrm{~m}$ ja rinnasdiameeter $30 \mathrm{~cm}$. Puud asuvad teiste puude varjus ja pole seetõttu viljunud. Endises Rõkka taimlas kasvab üks 60-aastane korea seedermänd, mis on kasvatatud Habarovski dendroloogiaaiast saadud seemnest. Puu kõrgus on $17 \mathrm{~m}$ ja rinnasdiameeter $26 \mathrm{~cm}$, kannab käbisid juba mitu aastat. Agali arboreetumis kasvab minipuistu, mis on rajatud 1967. a PPI õppe-katsemetsamajandist saadud seemnest. 23-aastaselt oli puistu keskmine kõrgus 6 meetrit (Kasesalu, 2000). Nüüd on suuremate puude kõrgus $17 \mathrm{~m}$ ja rinnasdiameeter $30 \mathrm{~cm}$.

Kääbus-seedermänd - Pinus pumila (Pall.) Regel. Seemned saadi Kamtšatkalt 1974. a. Kasvab noores eas aeglaselt. Külmakahjustusi pole esinenud. Kasvab nüüd kuni 3 m kõrguse põõsana. Mõnel aastal viljub rikkalikult. On väga dekoratiivne liik ning väärib edaspidi laialdasemat kasutamist pargimajanduses.

\section{Lehtpuud}

Haberoodne vaher - Acer barbinerve
Maxim. Seemned olid kogutud 1976. a sügisel Primorje kraist Ussuriiski rajoonist. Idanevus oli võrdlemisi hea. Külmakahjustusi pole esinenud. Kasvab Järvseljal kuni 4 m kõrguse põõsana. See üsna dekoratiivne põõsaliik võib osutuda sobivaks haljastustöödel.

Korea vaher - A. pseudosieboldianum (Pax) Kom. Seemned olid kogutud Ussuriiski rajoonist 1976. a sügisel. Idanevus oli hea, kuid taimed kannatasid külma all. Hiljem külmakindlus paranes. Nüüd kasvab Järvseljal kuni 9 m kõrguse põõsana. Mõnel aastal viljub rikkalikult. On väga dekoratiivne liik haljastustöödeks, eriti sügisel lehtede värvimuutuse ajal.

Pärnvaher - A. tegmentosum Maxim. Seemned olid kogutud 1976. aastal Ussuriiski rajoonist. Idanevus oli tagasihoidlik. Noores eas kannatas külma all. Nüüd kasvab Järvseljal 9 m kõrguse põõsana. On väga dekoratiivne ja omapärane liik, erinedes lehe kuju poolest kõigist teistest vahtraliikidest.

Südajas aktiniidia - Actinidia kolomikta (Rupr. et Maxim.) Maxim. Seemned saadi 1959. a Habarovski dendroloogiaaiast. Mõnel aastal kannatasid noored taimed hiliskülmade läbi. On tugede najal kasvanud rohkem kui 3 m kõrguseks. Öitseb igal aastal, viljumine on tagasihoidlik.

Kamtšatka lepp - Alnus kamtschatica (Regel) Kom. Seemned saadi 1976. a Kamtšatka Metsakatsejaamast. Puud kasvasid hulk aastaid normaalselt, küündides $6 \mathrm{~m}$ kõrgusele. Siis hakkasid nad aga ilma nähtava põhjuseta kuivama ja nüüdseks pole säilinud ühtki puud.

Dauuria kask - Betula davurica Pall. Seemned olid saadud 1972. a PPI õppekatsemetsamajandist. Kasvab Järvseljal kuni 18 m kõrguse puuna rinnasdiameetriga $22 \mathrm{~cm}$. Võrreldes teiste kaseliikidega, on puude kasv märksa kehvem, võra alumine osa on raagus. Tüve koor on tume ning omapäraselt kestendava tohuga.

Kivikask - B. ermanii Cham. Seeme saadi 1972. a Kamtšatkalt. Külmakahjustusi pole esinenud. Nüüd on puude suurim 
kõrgus $12 \mathrm{~m}$ ja rinnasdiameeter $12 \mathrm{~cm}$.

Lamedalehine kask - B. platyphylla Sukaczev. Seemned saadi 1959. a Habarovski dendroloogiaaiast. Nüüd on suurima puu kõrgus $24 \mathrm{~m}$ ja rinnasdiameeter $36 \mathrm{~cm}$. Külmakahjustusi pole esinenud. Puud on jõudsa kasvuga, kuid dekoratiivselt erilise väärtuseta.

Roideline kask - B. costata Trautv. Seemned olid kogutud 1976. aastal Ternei metsamajandist. Puukesed kasvasid suhteliselt aeglaselt ja kannatasid külma all. Agali arboreetumisse istutatud roidelised kased kasvasid kuni 5 m kõrguseks, kuid hakkasid siis kuivama. Viimane kask kuivas kolm aastat tagasi.

Südajas valgepöök - Carpinus cordata Blume. Seemned koguti 1976. a PPI õppe-katsemetsamajandist. Taimed olid aeglase kasvuga ja kannatasid külma all. Nüüd on suurima puu kõrgus $10 \mathrm{~m}$ ja rinnasdiameeter $12 \mathrm{~cm}$. Haljastuse seisukohalt sellel liigil Ida-Eesti tingimustes perspektiivi ei ole.

Erilehine sarapuu - Corylus heterophylla Fisch. et Trautv. Seemned saadi 1972. a PPI oppe-katsemetsamajandist. Taimed kasvasid suhteliselt aeglaselt. Külmakahjustusi pole esinenud. Mõnel aastal on ka viljunud. Nüüd kasvab Järvseljal kuni $4 \mathrm{~m}$ kõrguse põõsana.

Mandžuuria sarapuu - C. sieboldiana var. mandshurica (Maxim. et Rupr.) C. K. Schneid. Seemned saadi 1977. a Primorje kraist. Nüüd kasvab Järvseljal kuni $6 \mathrm{~m}$ kõrguse põõsana. Külmakahjustusi pole esinenud. Mõnel aastal on viljunud. Võib leida kasutamist haljastustöödel.

Maximowiczi viirpuu - Crataegus maximowiczii C. K. Schneid. ja sulglõhine viirpuu - Cr. pinnatifida Bunge kasvavad rahuldavalt. Külma läbi ei ole kannatanud. Mõlemad liigid viljuvad ja annavad idanemisvõimelist seemet.

Harilik eleuterokokk - Eleutherococcus senticosus (Rupr. et Maxim. ex Maxim.) Maxim. Seemned saadi 1967. a NSVL TA Mägitaiga Katsejaamast. Kasv on väga aeglane, kõrgus ei ületa $2 \mathrm{~m}$. Dekoratiivtai- mena tal väärtus puudub. Kaug-Idas hinnatakse seda põõsast ravimtaimena.

Mandžuuria saar - Fraxinus mandshurica Rupr. Seemned saadi 1966. a PPI õppe-katsemetsamajandist. Taimed kasvasid algul jõudsalt, kuid kannatasid väga tugevasti hiliskülmade all. Noored lehed läksid pärast tugevat hiliskülma mustaks ja langesid maha. Sellega oli jooksva aasta juurdekasv rikutud ning puud jäid kiduraks. Hiljem puude külmakindlus paranes. Nüüd on suuremate puude kõrgus $18 \mathrm{~m}$ ja rinnasdiameeter $18 \mathrm{~cm}$.

Nokjalehine saar - Fr.chinensis Roxb. var. rhynchophylla (Hance) Hemsl. Toodi noorte taimedena 1965. a Jaapani meres asuvalt Rikordo saarelt. Taimed kasvasid algul jõudsalt, kuid karmidel talvedel külmusid tagasi lumepiirini. Viimane tagasikülmumine oli 1978/79. a talvel. Nüüd on puukeste kõrgus $5 \mathrm{~m}$. Pakub huvi vaid kollektsiooniliigina.

Vahtralehik - Kalopanax septemlobus (Thunb.) Koidz. Istikud toodi 1969. a kevadel Tallinna Botaanikaaiast. Nüüd on endises nn Lossiaias kasvava puukese kõrgus 7 $\mathrm{m}$ ja rinnasdiameeter $12 \mathrm{~cm}$. Karmidel talvedel külmuvad noored võrsed tagasi. On väga dekoratiivne liik, kuid vähese külmakindluse tõttu haljastuses perspektiivitu.

Amuuri maakia - Maackia amurensis Rupr. et Maxim. Seeme saadi 1967. a PPI õppe-katsemetsamajandist. Olulisi külmakahjustusi pole esinenud. Nõuab viljakat kasvukohta. Nüüd on suuremate puude kõrgus $18 \mathrm{~m}$ ja rinnasdiameeter $26 \mathrm{~cm}$. On võrdlemisi dekoratiivne puu ja sobib kasutamiseks haljastustöödel.

Hiina prinseepia - Prinsepia sinensis (Oliv.) Oliv. ex Bean. Seemned saadi 1967. aastal NSVL TA Mägitaiga Katsejaamast. Järvseljal kasvab kuni ühe meetri kõrguse põõsana. Noores eas oli kasv võrdlemisi aeglane. Külmakahjustusi pole täheldatud. Pakub teatud huvi söödavate viljade poolest.

Aasia toomingas - Prunus padus L. var. pubescens Regel et Til. Seemned saadi 1974. a PPI õppe-katsemetsamajandist. 
Külmakahjustusi pole täheldatud. Kasvab Järvseljal kuni $10 \mathrm{~m}$ kõrguse põõsana. Liigil pole eeliseid hariliku toominga Prunus padus L. ees.

Amuuri toomingas - P. maackii Rupr. Seemned olid kogutud 1976. a sügisel Ussuriiski rajoonist. Külmakahjustusi pole märgatud. Suuremate puude kõrgus on 17 $\mathrm{m}$ ja rinnasdiameeter $30 \mathrm{~cm}$. On väga omapärane dekoratiivne puuliik, sobib haljastustöödeks.

Ussuuri pirnipuu - Pyrus ussuriensis Maxim. Seemned saadi 1973. a Primorje kraist. Suuremate puude kõrgus $16 \mathrm{~m}$ ja rinnasdiameeter $18 \mathrm{~cm}$. 1978/79. a talvel noored võrsed külmusid. Mõnel aastal viljub rikkalikult. On väga dekoratiivne kevadel õitsemise ajal. Võib leida kasutamist haljastustöödel.

Amuuri tamm - Quercus mongolica Fisch. ex Turcz. Toodi noorte taimedena 1965. a Rikordo saarelt. Kannatab külma all, võrsed on korduvalt lumepiirini tagasi külmunud. Kuna viimased talved on olnud suhteliselt soojad, siis on puu suutnud kasvada $9 \mathrm{~m}$ kõrguseks rinnasdiameetriga $12 \mathrm{~cm}$. 1977. a saadi partii seemneid Amuuri oblasti Blagovestšenski metsamajandist. Istikud kasvasid mõned aastad taimlas, siis ühel talvel hukkusid kõik.

Kähar tamm - Q. crispula Blume. Toodi 1969. a istikutena Tallinna Botaanikaaiast. Eelmise liigiga võrreldes kasvab märksa paremini. Endises Rõkka taimlas kasvab kaks puud, neist suurima kõrgus $15 \mathrm{~m}$ ja rinnasdiameeter $36 \mathrm{~cm}$. Külma talub paremini kui amuuri tamm. 1978/79. a karmil talvel oluliselt ei kannatanud.

Hiina sidrunväändik - Schisandra chinensis (Turcz.) Baill. Seemned saadi 1959. a Habarovski dendroloogiaaiast. Tugede najal on kasvanud kuni 3 m kõrguseks. Külmakahjustusi pole esinenud. Viljub ning annab idanemisvõimelist seemet. Tuleb hinnata kui dekoratiivset liiki vertikaalseks haljastuseks ning kui väärtuslikku marjakultuuri.

Lepalehine pihlakas - Sorbus alnifolia (Siebold et Zucc.) K. Koch. Istikud toodi
1971. a Luua puukoolist. Nüüd on puu kõrgus $10 \mathrm{~m}$ ja rinnasdiameeter $16 \mathrm{~cm}$. Külmakahjustusi pole esinenud. Esimest korda õitses 1982. aastal.

Leedrilehine pihlakas - S. sambucifolia (Cham. et Schleht.) Roem. Seemned saadi 1974. aastal Sahhalini Metsakatsejaamast. Järvseljal kasvab kuni ühe meetri kõrguse põõsana. Noores eas oli kasv väga aeglane. Pakub huvi dekoratiivtaimena ning söödavate viljade poolest.

Amuuri pärn - Tilia amurensis Rupr. Seemned olid kogutud 1974. a Ussuriiski rajoonist. Kasvas esimestel aastatel väga aeglaselt. Nüüd on suurima puu kõrgus 14 $\mathrm{m}$ ja rinnasdiameeter $28 \mathrm{~cm}$. Külmakahjustusi pole esinenud.

Regeli kolmtiivak - Tripterygium regelii Sprague et Takeda. Seemned saadi 1967. a NSVL TA Mägitaiga Katsejaamast. Külmakahjustusi pole esinenud. On kasvanud teise puu võrasse kuni 7 m kõrgusele. On võimalik kasutada vertikaalses haljastuses.

Madal jalakas - Ulmus pumila L. Seemned saadi 1972. a PPI õppe-katsemetsamajandist. Kasvab suhteliselt kiiresti, külmakahjustusi pole esinenud. Suuremate puude kõrgus on $16 \mathrm{~m}$ rinnasdiameetriga $30 \mathrm{~cm}$. Tänu omapärasele lehestikule on küllalt dekoratiivne ning väärib kasutamist haljastuses.

Peale ülalnimetatud liikide on ajavahemikus 1960-1980 Järvseljal katsetatud veel paljude Kaug-Ida päritoluga puude ja põõsaste kasvatamist, kuid praeguseks ajaks pole need säilinud. Ühed külmusid juba esimestel aastatel, teised hukkusid seenhaiguste tõttu. Aednike mitmekordse vahetuse tõttu on osa liike lihtsalt „kadunud“. Seoses uue jahilossi ehitamisega tuli senine nn Lossiaed likvideerida ja sealsed istikud ning heistrid teistesse taimlatesse üle viia. Paraku ei jõudnud kõik taimed uude asukohta. Endise Rõkka taimla müüs metskond hiljem eraisikule, kes aga ei hooldanud seda ning mitu seal kasvanud Kaug-Ida päritoluga liiki hukkusid. Mõned aastad kasvas taimlas üsna hästi kalmumänd (Pinus densiflora Siebold et Zucc.), 
siis aga kuivas ilmselt seenhaiguse tagajärjel. Lehtpuuliikidest kasvasid taimlas mõnda aega kollane vaher (Acer ukurunduense (Trautv. et C. A. Mey)), mõru aktiniidia (Actinidia polygama (Siebold et Zucc.) Maxim.) ja teravahambuline aktiniidia (A. arguta (Siebold et Zucc.) Planch. ex Miq.). Viimane kasvas tugede najal paari meetri kõrguseks, siis aga hävis. Veel kasvasid Järvseljal lühemat aega amuuri kukerpuu (Berberis amurensis Rupr.), raudkask (Betula schmidtii Regel), kahevärviline lespedeetsa (Lespedeza bicolor Turcz.), mandžuuria aprikoosipuu (Prunus mandshurica (Maxim.) Koehne), hambuline tamm (Quercus dentata Thunb.) ja mitu Kaug-Ida päritoluga kibuvitsa (Rosa sp.) liiki.

\section{Kokkuvõte}

Perioodil 1921-1980 Järvseljale introdutseeritud Kaug-Ida päritoluga puittaimed on Ida-Eesti tingimustes osutunud küllalt vastupidavaks ning kasvavad praegusel ajal rahuldavalt. Kuna Järvselja asub Eesti suhteliselt karmi kliimaga piirkonnas, kasvavad seal püsima jäänud puu- ja põosaliigid kindlasti ka teistes Eesti piirkondades. Ülalnimetatud ajavahemikul Järvseljale toodud Kaug-Ida puuliikidest on mõeldav kasutada metsakultiveerimisel jaapani, kuriili ja olga lehist, jaapani nulgu ning korea paplit. Valdav osa sel perioodil introdutseeritud puittaimedest võib leida kasutamist aga pargimajanduses. Aastail 1921-1940 sissetoodud puittaimedest on enamik oma koha pargimajanduses juba leidnud, seepärast vaadeldakse järgnevalt 1960-1980 introdutseeritud puude ja põosaste kasutamisvõimalust. Okaspuudest sobiksid haljastustöödeks järgmised liigid: mandžuuria nulg, korea nulg, mayri nulg, glehni kuusk, kääbus-seedermänd. Lehtpuu- ja põosaliikidest sobiksid selleks otstarbeks: haberoodne vaher, korea vaher, pärnvaher, südajas aktiniidia, dauuria kask, kivikask, erilehine sarapuu, maximowiczi viirpuu, sulglõhine viirpuu, amuuri maakia, amuuri toomingas, ussuuri pirnipuu, hiina sidrunväändik, amuuri pärn ja madal jalakas. Niisuguste liikide nagu kamtšatka nulu, hariliku eleuteroko$\mathrm{ki}$, nokjalehise saare, vahtralehiku, hiina prinseepia ja mongoolia tamme kasvatamine on Ida-Eesti tingimustes mõeldav põhiliselt dendroloogilistes kollektsioonides.

Liigirikas Kaug-Ida floristiline regioon on Eestile üheks tähtsamaks puittaimede introduktsiooni lähtealaks. Seepärast tuleb katseid sealsete liikide kasvatamisega jätkata ka edaspidi.

\section{Kasutatud kirjandus}

Berg, Fr. 1924. Orders of trees in the forests and parks of Sangaste. (Puuseltsid Sangaste metsas ja pargis). - Eesti Mets 15/16, 157-161; 17/18, 177-180, 19/20; 194-197. (In Estonian).

Haller, B. 1929. Plantations at the Training Forest District of the University of Tartu in Kastre-Peravald. (Kultuurid Tartu Ülikooli Õppemetskonnas Kastre-Peravallas). - Tartu Ülikooli Metsaosakonna toimetused, 13. 134 pp. (In Estonian).

Kasesalu, H. 1962. Training and Experimental Forest Enterprise of the Estonian Agricultural University as the centre for the distribution of foreign species. (Eesti Põllumajanduse Akadeemia õppe- ja katsemetsamajand võorpuuliikide levitamise baasina). - EPA teaduslike tööde kogumik / Transactions of the Estonian Agricultural University, 23, 7283. (In Estonian).

Kasesalu, H. 1982. On the results of growing tree and shrub species of Far-Eastern origin at Järvselja Training and Experimental Forest District. (KaugIda päritoluga puu- ja põõsaliikide kasvatamise tulemustest Järvselja õppe-katsemetsamajandis). - EPA teaduslike tööde kogumik / Transactions of the Estonian Agricultural University, 142, 104-116. (In Estonian).

Kasesalu, H. 1999. Cultivation of larches (Larix sp.) at Järvselja. (Lehiste kasvatamise tulemusi Järvseljal). - Metsanduslikud Uurimused / Forestry Studies, XXXI, 124-130. (In Estonian).

Kasesalu, H. 2000. Cultivation of introduced pines (Pinus spp.) at Järvselja. (Introdutseeritud mändide (Pinus spp.) kasvatamise tulemusi Järvseljal). - Metsanduslikud Uurimused / Forestry Studies, XXXII, 63-72. (In Estonian).

Klinge, J. 1883. Woody plants in Estonia, Livonia and Courland. (Die Holzgewächse von Est-, Liv- und Curland). Dorpat. 290 pp. (In German).

Laas, E. 1987. Dendrology. (Dendroloogia). Tallinn, Valgus. 823 pp. (In Estonian). 
Mathiesen, A. 1927. Training Forest District of the university. (Ülikooli Õppemetskond). - Tartu Ülikooli Metsaosakonna toimetused, 11. 111 pp. (In Estonian).

Mathiesen, A. 1940. About frost damage in trees and shrubs in the winter of 1939-1940. (Külmakahjustustest puudel ja põõsastel 1939.-1940.a. talvel). - Tartu Ülikooli Õppe- ja Katsemetskonna Teated, 10, 3-22. (In Estonian).

Ostrat, A. 1944. Plantations of Kuril larch ( $L$. Gmelini var. japonica Pilger) in the Training and Experimental Forest District of the University of Tartu. (Kuriili lehise (L. Gmelini var. japonica Pilger) kultuurid T. Ü. Ôppe- ja Katsemetskonnas). - Eesti Mets, 5, 89-91. (In Estonian).

Paivel, A. 1968. On the introduction of forein tree species and its perspectives in Soviet Estonia. (Võõrpuuliikide introduktsioonist ja selle perspektiividest Eesti NSV-s). - Paju, V. (ed.).
On the Introduction of Plants in Soviet Estonia. (Taimede introduktsioonist Eesti NSV-s). Tallinn, Valgus, 5-16. (In Estonian).

Sivers, M. 1889. An attempt to neutralize forest and park trees in Livonia. (Versuch einer Anleitung zur Naturalisation von Forst- und Parkbäume in Livland). - Mittheilungen der Kaiserlichen Livländischen Gemeinnützigen und Oeconomischen Sotsietät in Dorpat, 12, 25-32. (In German).

Veermets, K. 1962. On scientific research and experimental work in the Training and Experimental Forest Enterprise of the Estonian Agricultural University in 19451960. (Teaduslikust uurimis- ja katsetööst Eesti Põllumajanduse Akadeemia õppe- ja katsemetsamajandis aastail 1945-1960). - EPA teaduslike tööde kogumik / Transactions of the Estonian Agricultural University, 23, 4651. (In Estonian). 


\section{The results of cultivating tree and shrub species of Far- Eastern origin at Järvselja}

\section{Heino Kasesalu}

\section{Summary}

The first foreign tree species were introduced into the forests of the Järvselja Training and Experimental Forest District in the 1880s. At that time Martin Maurach had taken up the post of a forester here. The first nursery at Järvselja was established in 1887 in order to produce planting stock. In addition to native species, the seeds obtained from abroad were sown, too. Cultivation of foreign tree species in a forest pursued an aesthetic goal on the one hand and an experimental aim on the other. Foreign tree species were cultivated mainly in groups mixed with local species. From that period Larix kaempferi is growing in the central park of the forest district with a height of $37.5 \mathrm{~m}$ and breast height diameter of $92 \mathrm{~cm}$.

In 1921, the Training and Experimental Forest District of the University of Tartu was established at Järvselja. The cultivation of foreign tree species was carried out under Andres Mathiesen's guidance. An arboretum, about two hectares in area, founded in 1935 is located near the centre of Järvselja. Various exotic species, mainly conifers, were planted in a thinned birch stand.

Of the firs of Far-Eastern origin, Abies sachalinensis, A. veitchii, A. nephrolepis and A. homolepis were planted here. The last species was sensitive to frost. Of the conifers, Picea jezoensis, Pinus koraiensis and Taxus cuspidata grow in the arboretum.

Larix gmelinii var. japonica was cultivated in the forest as little forest stands mainly in Myrtillus site type. This species grew in the forest better than other larch species. At that time, several broadleaved trees and shrubs were cultivated at Järvselja, too, such as Juglans mandshurica, Phellodendron amurense, Populus koreana, Pterocarya rhoifolia, Rhododendron dauricum, Syringa amurensis, Acer ginnala, Rosa rugosa, Vitis amurensis and others. All these species are now growing normally. Before the Second World War, Järvselja was one of the largest bases for the propagation of foreign tree species in Estonia. Exotic seedlings cultivated at Järvselja have been introduced in almost all areas of Estonia.

In the first years after the war, no foreign tree species were introduced in Järvselja. This activity was revived in 1953 on the iniative of Endel Laas. Since 1964, the author of this paper has been involved in the introduction of foreign tree species in Järvselja. Many new tree and shrub species of Far-Eastern origin have been introduced in Järvselja. A new arboretum on former arable land was established in 1968 at Agali village where foreign tree species were planted as little forest stands. Part of the foreign tree species died due to frost during harsh winters or perished for other reasons. For forest cultivation, Larix kaempferi, L.gmelinii var. japonica, L.gmelinii var. olgensis, Abies veitchii and Populus koreana may be used. More promising conifer species for park management are Abies holophylla, A. koreana, A. sachalinensis var. mayriana, Picea glehnii, Pinus pumila. Of broadleaved trees and shrubs the following suit this purpose: Acer barbinerve, A. pseudosieboldianum, A. tegmentosum, Betula davurica, B. ermanii, Corylus heterophylla, Crataegus maximowiczii, Cr.pinnatifida, Maackia amurensis, Prunus maackii, Pyrus ussuriensis, Schisandra chinensis, Tilia amurensis, Ulmus pumila. Species such as Abies sachalinensis var. gracilis, Eleutherococcus senticosus, Fraxinus chinensis var. rhynchophylla, Kalopanax septemlobus, Prinsepia sinensis are of importance chiefly from the standpoint of dendrological collection. 